\title{
External cooling efficiently controls intraosseous temperature rise caused by drilling in a drilling guide system: an in vitro study
}

Kristof Boa, MD ${ }^{\mathrm{a}}$, Endre Varga Jr., DDS, PhD ${ }^{\mathrm{b}}$, Gabor Pinter, MD, DDS ${ }^{\mathrm{c}}$, Akos Csonka, MD ${ }^{\mathrm{d}}$, Istvan Gargyan, $\mathrm{MD}^{\mathrm{e}}$, Endre Varga, MD, PhD ${ }^{\mathrm{f}}$.

*Corresponding author: ${ }^{a}$ PhD student, Department of Trauma Surgery, University of Szeged, Szeged, Hungary; Semmelweis u. 6., H-6725, Szeged, Hungary, Phone: 0036204353329, Fax: 003662545530, e-mail: boa.kristof@gmail.com

${ }^{b}$ Head of scientific research \& development, DicomLab Kft., Szeged, Hungary; Pulz u. 46/B, H-6724, Szeged, Hungary, Phone: 0036305020368, e-mail: endrevargadmd@yahoo.com

c PhD student, Department of Trauma Surgery, University of Szeged, Szeged, Hungary; Semmelweis u. 6., H-6725, Szeged, Hungary, Phone: 0036703344024, e-mail: pinterga@redmen.hu

d Orthopedics \& trauma specialist, Department of Trauma Surgery, University of Szeged, Szeged, Hungary; Semmelweis u. 6., H-6725, Szeged, Hungary, Phone: 003662541784, email: csonka.akos81@gmail.com

e Senior trauma consultant, Department of Trauma Surgery, University of Szeged, Szeged, Hungary; Semmelweis u. 6., H-6725, Szeged, Hungary, Phone: 003662545537, e-mail: istvangargyandr@gmail.com

${ }^{f}$ Head Professor of Trauma Surgery, Department of Trauma Surgery, University of Szeged, Szeged, Hungary; Semmelweis u. 6., H-6725, Szeged, Hungary, Phone: 003662545531, email: endrevargamd@yahoo.com 
External cooling efficiently controls intraosseous temperature rise caused by drilling in a drilling guide system: an in vitro study 


\section{Abstract}

Purpose

The purpose of this study was to measure the intraosseous temperature rise caused by drilling in a drilling guide system.

\section{Materials and Methods}

Generated temperature rise and number of temperature rises exceeding $10^{\circ} \mathrm{C}$ was compared between cooling and no cooling for every step of the drilling sequence. Standard saline on room temperature $\left(25^{\circ} \mathrm{C}\right)$ was used as coolant. Bone specimens were cortical layers of bovine ribs. Drilling was performed through 3D-printed surgical guides. Heat measurements were performed with an infrared thermometer. Statistical analysis: either two-sample t-test or Welch's t-tests was performed depending on the variances.

Results

Mean temperature rise with number of temperature rises exceeding $10^{\circ} \mathrm{C}$ per number of measurements in brackets were the following: $4.8^{\circ} \mathrm{C}(0 / 48)$ with cooling and $7.0^{\circ} \mathrm{C}(8 / 48)$ without cooling in case of $2.0 \mathrm{~mm}$ drilling, $5.2^{\circ} \mathrm{C}(1 / 48)$ with cooling and $8.5^{\circ} \mathrm{C}(17 / 48)$ without cooling in case of $2.5 \mathrm{~mm}$ drilling of the $2.0 \mathrm{~mm}$ canal, $3.3^{\circ} \mathrm{C}$ with cooling $(0 / 48)$ and $8.5^{\circ} \mathrm{C}(18 / 24)$ without cooling in case of $3.0 \mathrm{~mm}$ drilling of the $2.5 \mathrm{~mm}$ canal, $4.8^{\circ} \mathrm{C}$ with cooling (0/24), $9.4^{\circ} \mathrm{C}$ without cooling $(10 / 23)$ in case of $3.5 \mathrm{~mm}$ drilling of the $3.0 \mathrm{~mm}$ canal. The temperature rise was significantly lower when cooling in every step of the drilling sequence.

Conclusions 
Use of external cooling can sufficiently hold intraosseous temperature in the safe range, while drilling through an implant guide system whereas drilling without irrigation can lead to temperatures exceeding the accepted limit in the same setting.

Keywords: Implants; Implant site preparation; Patient-specific guide; Drilling guide; Intraosseous temperature rise; Cooling; Drilling. 


\section{Introduction}

Bone drilling is a frequently used method in several fields of medicine, including orthopaedic surgery, neurosurgery, cranio-maxillofacial surgery and dentistry. The generated frictional heat leads to an intraosseous temperature rise. It is widely accepted that bony temperature should stay below $47^{\circ} \mathrm{C}$ as it is established in studies done by Eriksson and Adell $^{1}$ and Eriksson and Albrektsson. ${ }^{2}$ When temperature exceeds this value, thermal osteonecrosis can develop, leading to fatty tissue replacing the bone in the affected area, compromising osseointegration of the implant. ${ }^{3}$

More and more evidence support the idea that the use of patient-specific drilling guides can provide improved accuracy in implant dentistry, including a recent prospective randomized clinical study. ${ }^{4}$ As more soft tissue and the guide itself surround the area of drilling, concerns may arise about the heat conduction during drilling. Misir et al. have concluded that drilling with the use of a surgical drilling guide generates more heat than it is generated during conventional implant site preparation. ${ }^{5}$ Jeong et al.'s investigation using a wood-and-silicone model and have concluded that there is no significant difference between guided flapless and flap technique. ${ }^{6}$ Migliorati et al. have compared open-flap standard surgery, flapless standard surgery, open-flap guided surgery and guided flapless surgery, concluding that while guided surgery produces bigger rise of the bony temperature, the temperature stays in the safe zone in the latter cases as well. ${ }^{7}$ Comparing guided surgery to the conventional technique, dos Santos et al. have found the temperature elevation to stay within the safe zone as well. $^{8}$ 
As this technique emerges, we think that further elucidation of the topic is of big importance. 


\section{Materials and Methods}

Drilling was performed on cortical bovine rib bones. The use of bovine bone is beneficial because of its thermophysical and anatomical properties, as well as its good availability and easy handling. Davidson et al. have shown that bovine cortical bone is thermally isotropic and the value of its conductivity is likely to be around that of the human cortical bone. ${ }^{9}$ Yacker et al have performed CT scan of bovine bones and have concluded that bovine cortical density is about 1,400 Hounsfield units, while typical human mandible cortical density is between 1,400 and 1,600 Hounsfield units. ${ }^{10}$ Cortical bone thickness of the human mandible has been investigated in 2007 by Katranji et al., finding the average edentulous cortical thickness to be between 1.0 and $2.0 \mathrm{~mm}$ and the dentate cortical thickness between 1.6 and $2.2 \mathrm{~mm} .{ }^{11}$ Value of thickness amongst our bovine rib specimens varied between $1.5 \mathrm{~mm}$ and $2.7 \mathrm{~mm}$, suggesting that its anatomical properties are comparable to that of the human mandible. These data from the literature and our own anatomical measurements suggest that bovine rib bones provide a good model of the human mandible for scientific experiments.

The ribs were derived from the same animal and were treated as described by Sedlin and Hirsch ${ }^{12}$ : the specimens were frozen to $-10^{\circ} \mathrm{C}$ in saline solution when not used. Before the measurements took place the specimens were warmed to $36 \pm 1^{\circ} \mathrm{C}$. Baseline temperature of the bone was checked before every drilling. If the baseline temperature was below $35^{\circ} \mathrm{C}$ the specimen was placed back in the warming device.

Infrared thermographic studies performed by Augustin et al. have shown that the generated temperature rise reaches its peak in the cortical layer of the bone ${ }^{13}$, thus we designed an 
experimental setting in which we can measure the bony temperature around the drilled canal right before it reaches through the cortical layer, representing the peak of intraosseous heat generation. Flat parts of the bovine ribs were divided and cut into segments as long as attachment of the surgical guide containing $3 \times 8$ drilling holes to it was possible. After that, the edges were cut from the ribs in a longitudinal fashion, followed by cutting the specimens into two halves through its cancellous bone layer, parallel to the flat surface of the bone. This was followed by the removal of the remaining cancellous bone tissue with a chisel. Thus, we could prepare quasi flat bone specimens containing only the cortical layer. (Figure 1.)

Heat measurement was performed with an infrared thermometric device (Voltcraft IR-380). The device is equipped with two lasers crossing each other at the focus point of the infrared measurement, providing good ability to aim the device at the point of exit of the drill. In case of drilling through a preformed canal of lesser diameter by $0.5 \mathrm{~mm}$ (as it happens from the $2^{\text {nd }}$ step of the drilling sequence), the thermometer was pointed immediately next to the exit of the canal. (Figure 3.)

As the specimens were flat cortical parts of the bovine ribs, a universal surgical guide was designed containing 24 guiding canals in 3 columns (Figure 2.). The guide was manufactured using the same standards as the guides of the Smart Guide system (Smart Dental Solutions Ltd., Szeged, Hungary), 3D printed (printer: ProJet 3510 MP), using the same material (VisiJet Stoneplast). Fixation was available by inserting the system's standard pins into pin holes placed in the four corners.

Drilling was performed by the same experienced dentoalveolar surgeon (being author Gábor Pintér) in order to achieve quasi constant applied pressure. Slight pumping drilling motion to 
facilitate the transfer of the heated debris from the canal was applied. The surgeon was not able to see the screen of the thermometer (Figure 3.), thus it was not affecting his usual drilling motion and the pressure applied by him. Drill speed was set to a constant 800 RPM as it is advised by the manual of the Smart Guide system used in this study.

Every step of the drilling sequence was investigated. The applied implant preparation system includes the subsequent use of drills of the following diameters: $2.0 \mathrm{~mm}, 2.5 \mathrm{~mm}, 3.0 \mathrm{~mm}$, and $3.5 \mathrm{~mm}$.

External cooling was applied by the assistant with a standard $50 \mathrm{ml}$ syringe at the point of the drill entering the metal sleeve of the canal in the drilling guide (Figure 3.). Standard saline solution at a room temperature of $25^{\circ} \mathrm{C}$ was used as coolant liquid. The drills were washed and cooled back to room temperature after every single drilling.

Baseline temperature and peak temperature of the exit point was acquired by reviewing the videos. Temperature rise was calculated by extracting baseline temperature from peak temperature with the latter being read right before the appearance of the drill bit, thus representing the bony temperature and not the temperature of the drill material. The values of temperature rise were collected in comma separated values file format using Microsoft Excel. Statistical analysis was performed using the open-source RStudio software. In case of similar variances two-sample t-test, while in case of differing variances Welch's t-test was performed. Level of significance was established a priori at $\alpha=0.05$. 


\section{Results}

The first step of the implant system's drilling sequence is drilling with the $2.0 \mathrm{~mm}$ pilot drill. 48 drillings performed with the use of external irrigation produced a mean temperature rise of $4.77^{\circ} \mathrm{C}$, while in case of 48 drillings performed without the use of external cooling it was $7.02^{\circ} \mathrm{C}$ (Table 1.). The difference was statistically significant $(p<0.001)$. Eight times out of the 48 drillings performed did the rise exceed the $10^{\circ} \mathrm{C}$ threshold on the latter case, while no drilling exceeded it if external cooling was applied (Table 2.).

During the second step of the drilling sequence (being $2.5 \mathrm{~mm}$ drilling of the $2.0 \mathrm{~mm}$ canal) the mean temperature rise was $5.22^{\circ} \mathrm{C}$ with cooling, and $8.48^{\circ} \mathrm{C}$ without cooling (Table 1.). The difference was statistically significant $(p<0.001)$. Number of measured temperature rises exceeding the threshold was 1 out of 48 with cooling and 17 out of 48 without cooling (Table 2.).

Throughout the third step of the drilling sequence (being $3.0 \mathrm{~mm}$ drilling of the $2.5 \mathrm{~mm}$ canal) the mean temperature rise was $3.32^{\circ} \mathrm{C}$ with cooling, and $8.48^{\circ} \mathrm{C}$ without cooling (Table 1.). The difference was statistically significant $(p<0.001)$. No cases out 48 drillings exceeded the threshold for temperature rise with the use of external irrigation, while without the use of it 18 times out of the 24 performed drilling was the increase exceeding the limit (Table2.).

During the fourth step of the drilling sequence (being $3.5 \mathrm{~mm}$ drilling of the $3.0 \mathrm{~mm}$ canal) the mean temperature rise was $4.75^{\circ} \mathrm{C}$ if external cooling was applied, and $9.40^{\circ} \mathrm{C}$ if no external cooling was applied (Table1.). The difference was statistically significant $(p<0.001)$. Number of measured temperature rises exceeding the threshold was 0 out of 24 with cooling and 10 out of 24 without cooling (Table 2.). 
Boxplot diagram presentation of the distribution of measured temperature rises can be seen on Figure 4. 


\section{Discussion}

Temperature rise caused by drilling was significantly lower in case of external irrigation, compared to no cooling for every step of the drilling sequence. Using external irrigation, the mean elevation varied between $3.32^{\circ} \mathrm{C}$ and $5.22^{\circ} \mathrm{C}$, whereas the use of no cooling resulted in a mean temperature rise varying between $7.02^{\circ} \mathrm{C}$ and $9.40^{\circ} \mathrm{C}$. While the mean elevation stayed below $10^{\circ} \mathrm{C}$ despite using no cooling method, several measurements showed temperature rises exceeding the established limit of $10^{\circ} \mathrm{C}$. External cooling efficiently held bony temperature in the safe zone with only one outlier measurement showing an elevation slightly exceeding $10^{\circ} \mathrm{C}$. However, the latter phenomenon may require further elucidation and consideration.

As it is the last step of the preparation sequence and the affected tissue is not removed by subsequent drillings, it needs to be emphasized that $3.5 \mathrm{~mm}$ drilling with external irrigation did only generate a mean temperature elevation of $4.75^{\circ} \mathrm{C}$ with no measurement exceeding the limit. As 10 times out of 24 drillings performed with the $3.5 \mathrm{~mm}$ drill without cooling resulted in the temperature exceeding the limit, the use of no cooling can be considered potentially harmful.

Misir et al. have been investigating heat generation on bovine femoral specimens finding the mean maximum bony temperature to be $37.9^{\circ} \mathrm{C}$ with surgical guides and $30.2^{\circ} \mathrm{C}$ without surgical guides, however only the mean baseline temperature of $30.1^{\circ} \mathrm{C}$ was published ${ }^{5}$, also as bovine femoral cortical anatomy is different from bovine rib anatomy, we cannot compare temperature rises with our data. Jeong et al. have compared guided flapless technique to flap technique on a wood-and-silicone model with the wood representing the 
same density as human bone. They have found no significant difference between the two approaches and thus concluded that external irrigation with up-and-down pumping motions can provide a safe technique in implant site preparation ${ }^{6}$. This is in consonance with our results, showing external irrigation to hold bony temperature in the safe zone with the guided flapless technique. Migliorati et al. have performed heat measurements on pig rib bones, comparing open-flap technique to guided flapless technique. They have found significantly higher peak bony temperature with the guided technique, however, the intraosseous temperature has remained in the safe zone. ${ }^{7}$ Dos Santos et al. have been investigating heat generation during guided surgery on rabbit tibias. While they have found the guided surgery to generate higher temperatures compared to classical techniques, no temperature elevation has exceeded $5.8^{\circ} \mathrm{C}$, thus they concluded the guided technique to be safe from an osteonecrosis point of view. ${ }^{8}$

Limitation of our study is its in vitro nature, however, intraoperative in vivo measurement of bony temperature rise might be difficult.

Strength of our study is the experimental setting to measure heat right before the drill bit reaches through the cortical layer of the bone, thus we suggest that it provides a good estimation of the peak bony temperature compared to studies using thermocouples placed in a distance from the drilled canal. Further strength of the study is investigating the thermal consequences of drilling in a guided surgery setting. 


\section{Conclusions}

As the guided technique's potential of improving accuracy is getting supported by more and more evidence, it is very important to investigate potentially harmful aspects of its usage. Our findings suggest that despite the fact that more soft tissue and the surgical guide itself surround the area of implant preparation, external irrigation can efficiently control and hold bony temperature in the safe zone while using the flapless guided surgery technique. In conclusion: according to our results, guided flapless surgery using 3D printed surgical guides can be safely used with external irrigation as a coolant method. 


\section{Conflict of Interest statement}

Author Endre Varga Jr., DDS, PhD is the head of research \& development at DicomLab Kft.,Szeged, Hungary, manufacturer of 3D-printed patient-specific drilling guides. Author Prof. Endre, Varga, MD, $\mathrm{PhD}$ is the senior consultant of computer-aided surgical techniques at DicomLab Kft., Szeged, Hungary, manufacturer of 3D-printed patient-specific drilling guides.

No other author has any financial connection with a commercial partner.

\section{Acknowledgements}

The authors would like to thank Balázs Erdőhelyi and Balázs Bagó software engineers of the DicomLab Kft.,Szeged, Hungary for providing the specialized surgical guides, Jenő Huszka of the DicomLab Kft.,Szeged, Hungary for providing the surgical trays for the experiments, Ferenc Ignácz research fellow, physicist of the Department of Optics and Quantum Electronics, University of Szeged for his help in designing and implementing heat measurement of the experimental setting.

The study was funded by the Új Széchenyi Terv funding programme (GOP-1.1.1-11-20120372). 
1. Eriksson R, Adell R. Temperatures during Drilling for the Placement of Implants using the Osseointegration Technique. J Oral Maxillofac Surg 1986;44:4-7.

2. Eriksson A, Albrektsson T, Albrektsson B. Heat Caused by Drilling Cortical Bone -

Temperature Measured Invivo in Patients and Animals. Acta Orthop Scand 1984;55:629-631.

3. Eriksson A, Albrektsson T, Grane B, McQueen D. Thermal-Injury to Bone - a VitalMicroscopic Description of Heat-Effects. Int J Oral Surg 1982;11:115-121.

4. Vercruyssen M, Cox C, Coucke W, Naert I, Jacobs R, Quirynen M. A randomized clinical trial comparing guided implant surgery (bone- or mucosa-supported) with mental navigation or the use of a pilot-drill template. J Clin Periodontol 2014;41:717-723.

5. Misir AF, Sumer M, Yenisey M, Ergioglu E. Effect of Surgical Drill Guide on Heat Generated From Implant Drilling. J Oral Maxillofac Surg 2009;67:2663-2668.

6. Jeong S, Yoo J, Fang Y, Choi B, Son J, Oh J. The effect of guided flapless implant procedure on heat generation from implant drilling. J Cranio-MaxilloFac Surg 2014;42:725-729.

7. Migliorati M, Amorfini L, Signori A, Barberis F, Biavati AS, Benedicenti S. Internal Bone Temperature Change During Guided Surgery Preparations for Dental Implants: An In Vitro Study. Int J Oral Maxillofac Implants 2013;28:1464-1469.

8. dos Santos PL, Queiroz TP, Margonar R, Gomes de Souza Carvalho,Abrahao Cavalcante, Betoni W, Jr., Rodrigues Rezende RR, et al. Evaluation of Bone Heating, Drill Deformation, and Drill Roughness After Implant Osteotomy: Guided Surgery and Classic Drilling Procedure. Int J Oral Maxillofac Implants 2014;29:51-58.

9. Davidson SRH, James DF. Measurement of thermal conductivity of bovine cortical bone. Med Eng Phys 2000;22:741-747.

10. Yacker MJ, Klein M. The effect of irrigation on osteotomy depth and bur diameter. Int J Oral Maxillofay Implants 1986;11:634.

11. Katranji A, Misch K, Wang H. Cortical bone thickness in dentate and edentulous human cadavers. J Periodontol 2007;78:874-878.

12. Sedlin ED, Hirsch C. Factors affecting the determination of the physical properties of femoral cortical bone. Acta orthop Scandinav 1966;37:29-48.

13. Augustin G, Davila S, Udiljak T, Vedrina DS, Bagatin D. Determination of spatial distribution of increase in bone temperature during drilling by infrared thermography: preliminary report. Arch Orthop Trauma Surg 2009;129:703-709. 


\section{Tables}

\begin{tabular}{|c|c|c|c|c|c|c|c|}
\hline $\begin{array}{l}\text { drilling } \\
\text { speed } \\
\text { (RPM) }\end{array}$ & $\begin{array}{c}\text { diameter of } \\
\text { the canal ( } \mathrm{mm})\end{array}$ & $\begin{array}{c}\text { drill } \\
\text { diameter } \\
(\mathrm{mm})\end{array}$ & cooling & $\begin{array}{c}\operatorname{mean}_{\Delta \mathrm{T}} \\
\left({ }^{\circ} \mathrm{C}\right)\end{array}$ & SD & $\mathbf{n}$ & $\begin{array}{c}\text { p-value } \\
(*<0.001)\end{array}$ \\
\hline 800 & 0.0 & 2.0 & + & 4.77 & 1.90 & 48 & \multirow{2}{*}{$7.438 \times 10^{-06} *$} \\
\hline 800 & 0.0 & 2.0 & - & 7.02 & 2.67 & 48 & \\
\hline 800 & 2.0 & 2.5 & + & 5.22 & 1.36 & 48 & \multirow{2}{*}{$2.068 \times 10^{-08 *}$} \\
\hline 800 & 2.0 & 2.5 & - & 8.48 & 3.25 & 48 & \\
\hline 800 & 2.5 & 3.0 & + & 3.32 & 1.23 & 48 & \multirow{2}{*}{$9.974 \times 10^{-14} *$} \\
\hline 800 & 2.5 & 3.0 & - & 8.48 & 2.95 & 24 & \\
\hline 800 & 3.0 & 3.5 & + & 4.75 & 1.28 & 24 & \multirow{2}{*}{$5.138 \times 10^{-06} *$} \\
\hline 800 & 3.0 & 3.5 & - & 9.40 & 3.73 & 23 & \\
\hline
\end{tabular}

Table 1.: Number of drillings, mean of temperature rise, standard deviation, and level of significance comparing cooling to no cooling for every step of the drilling sequence. 


\begin{tabular}{|c|c|c|c|c|c|}
\hline $\begin{array}{c}\text { drill } \\
\text { speed } \\
\text { (RPM) }\end{array}$ & $\begin{array}{l}\text { diameter of } \\
\text { the canal }(\mathrm{mm})\end{array}$ & $\begin{array}{l}\text { drill diameter } \\
(\mathrm{mm})\end{array}$ & cooling & $n_{\geq 10^{\circ} \mathrm{C}} / \mathrm{n}$ & $\% n_{\geq 10^{\circ} \mathrm{C}}$ \\
\hline 800 & - & 2.0 & + & $0 / 48$ & $0.0 \%$ \\
\hline 800 & - & 2.0 & - & $8 / 48$ & $16.7 \%$ \\
\hline 800 & 2.0 & 2.5 & + & $1 / 48$ & $2.1 \%$ \\
\hline 800 & 2.0 & 2.5 & - & $17 / 48$ & $35.4 \%$ \\
\hline 800 & 2.5 & 3.0 & + & $0 / 48$ & $0,0 \%$ \\
\hline 800 & 2.5 & 3.0 & - & $18 / 24$ & $75.0 \%$ \\
\hline 800 & 3.0 & 3.5 & + & $0 / 24$ & $0.0 \%$ \\
\hline 800 & 3.0 & 3.5 & - & $10 / 24$ & $43.5 \%$ \\
\hline
\end{tabular}

Table 2.: Number of temperature rises exceeding $10^{\circ} \mathrm{C}\left(\mathrm{n}_{\geq 10^{\circ} \mathrm{C}}\right)$ and proportion of these amongst measurements $\left(\% \mathrm{n}_{\geq 10^{\circ} \mathrm{C}}\right)$ for every step of the drilling sequence. 


\section{Figure 1.}

Click here to download high resolution image

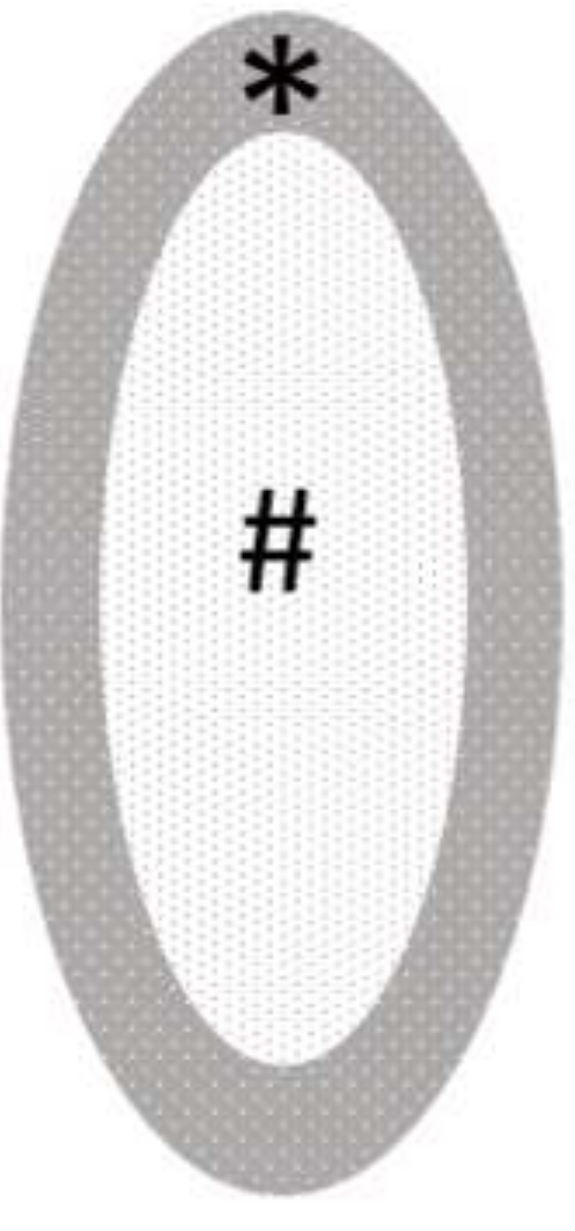

(a)

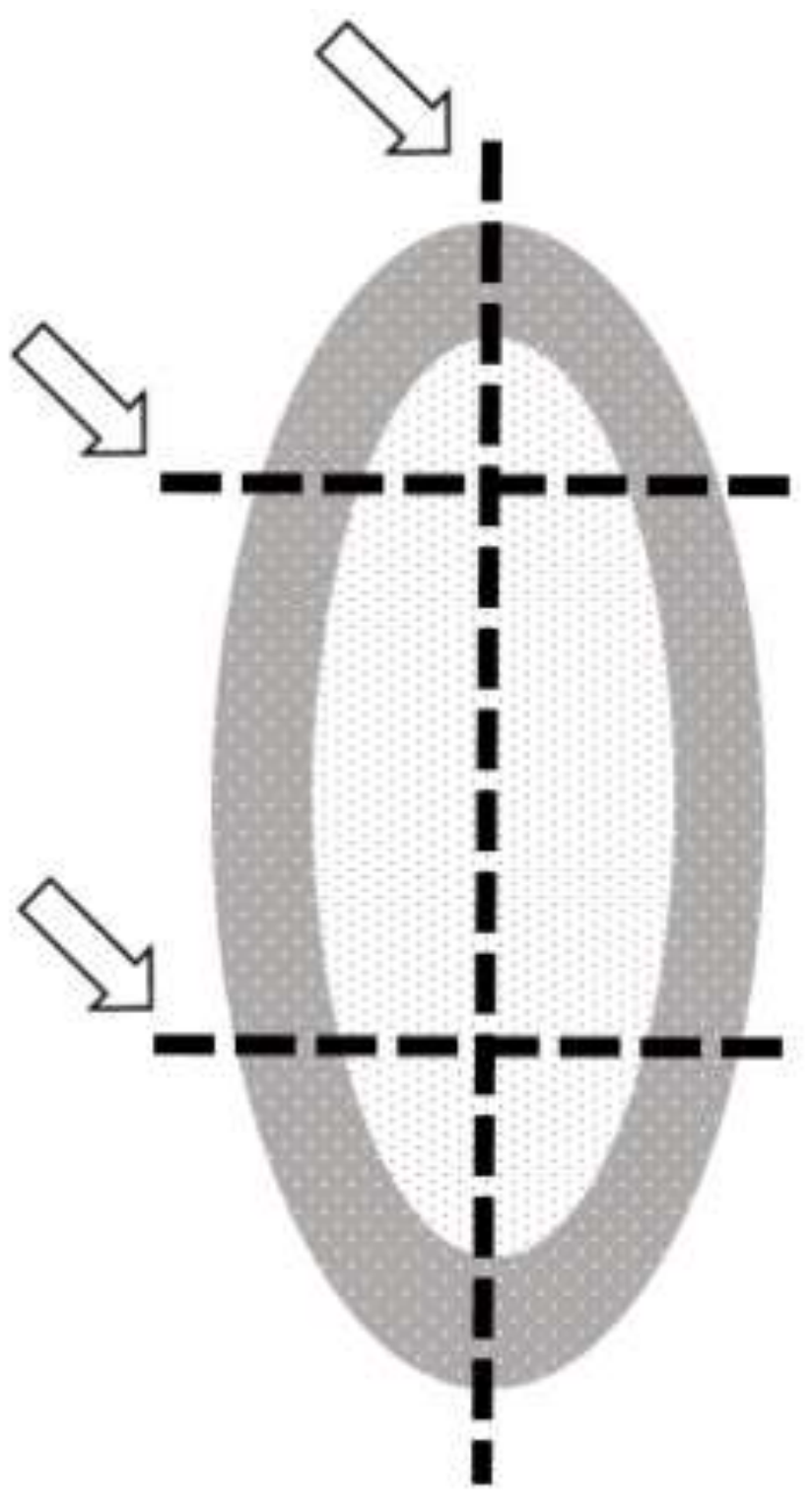

(b)

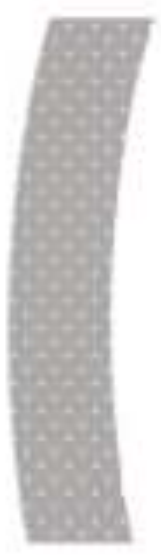



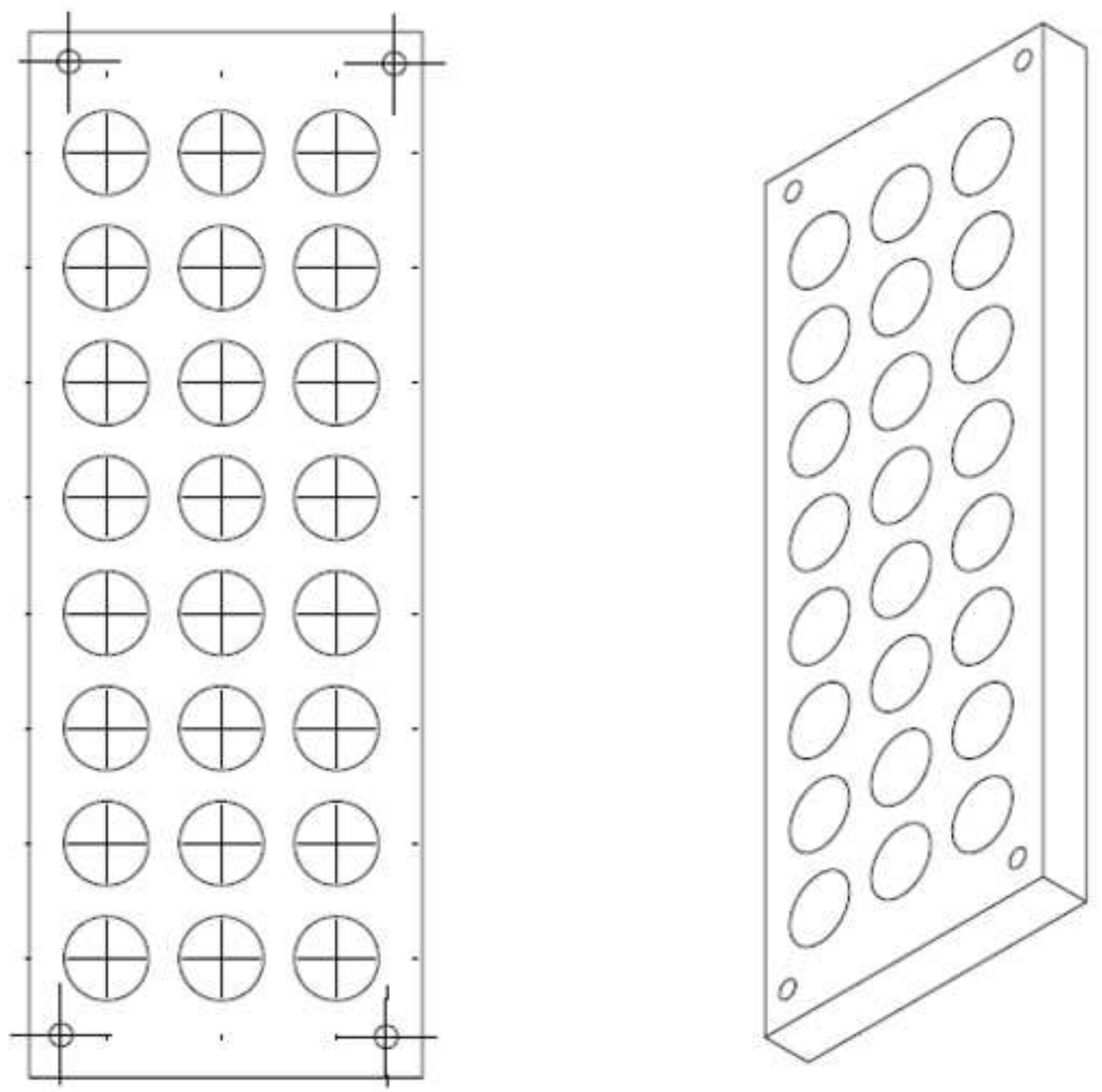
Figure 3.

Click here to download high resolution image

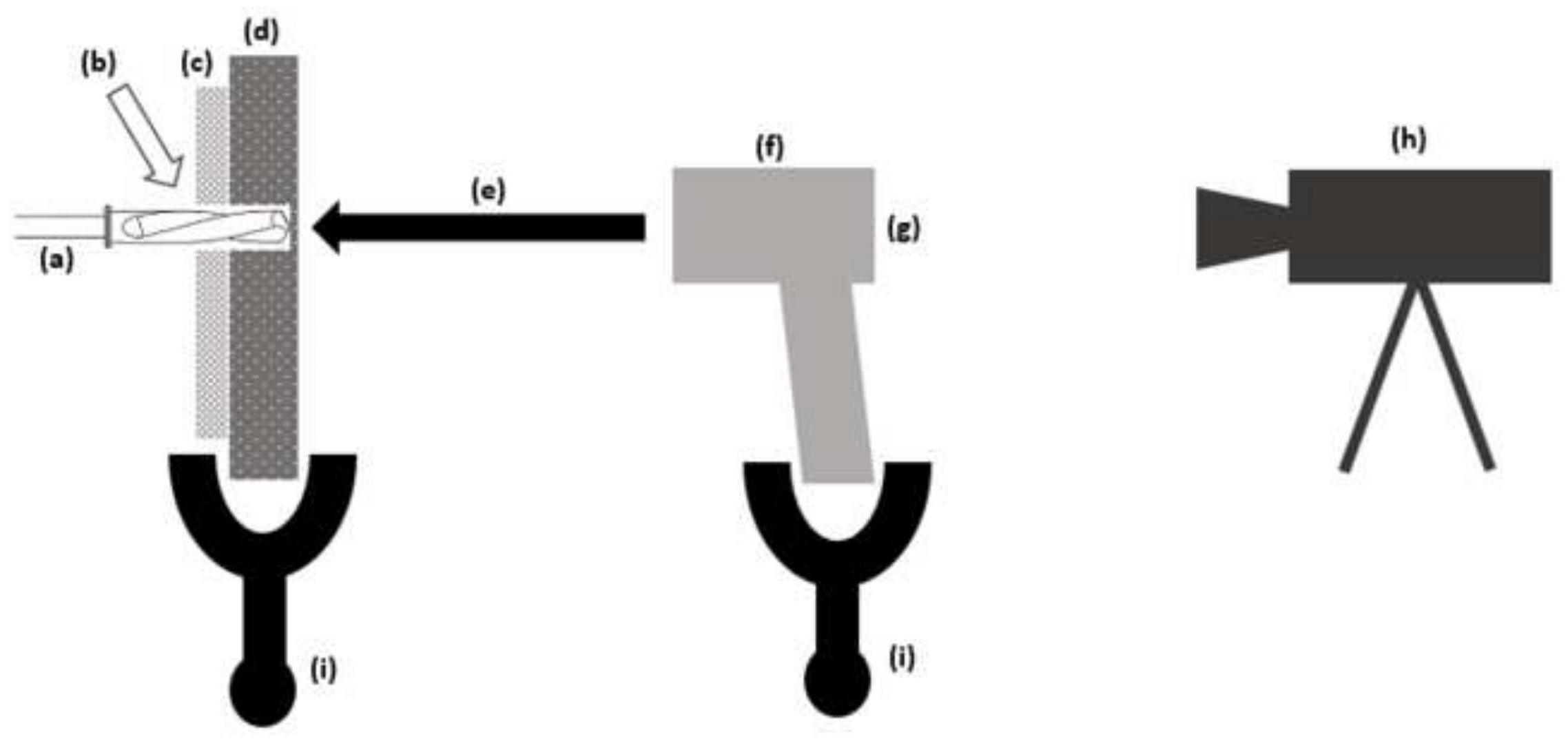


Figure 4.
Click here to download high resolution image

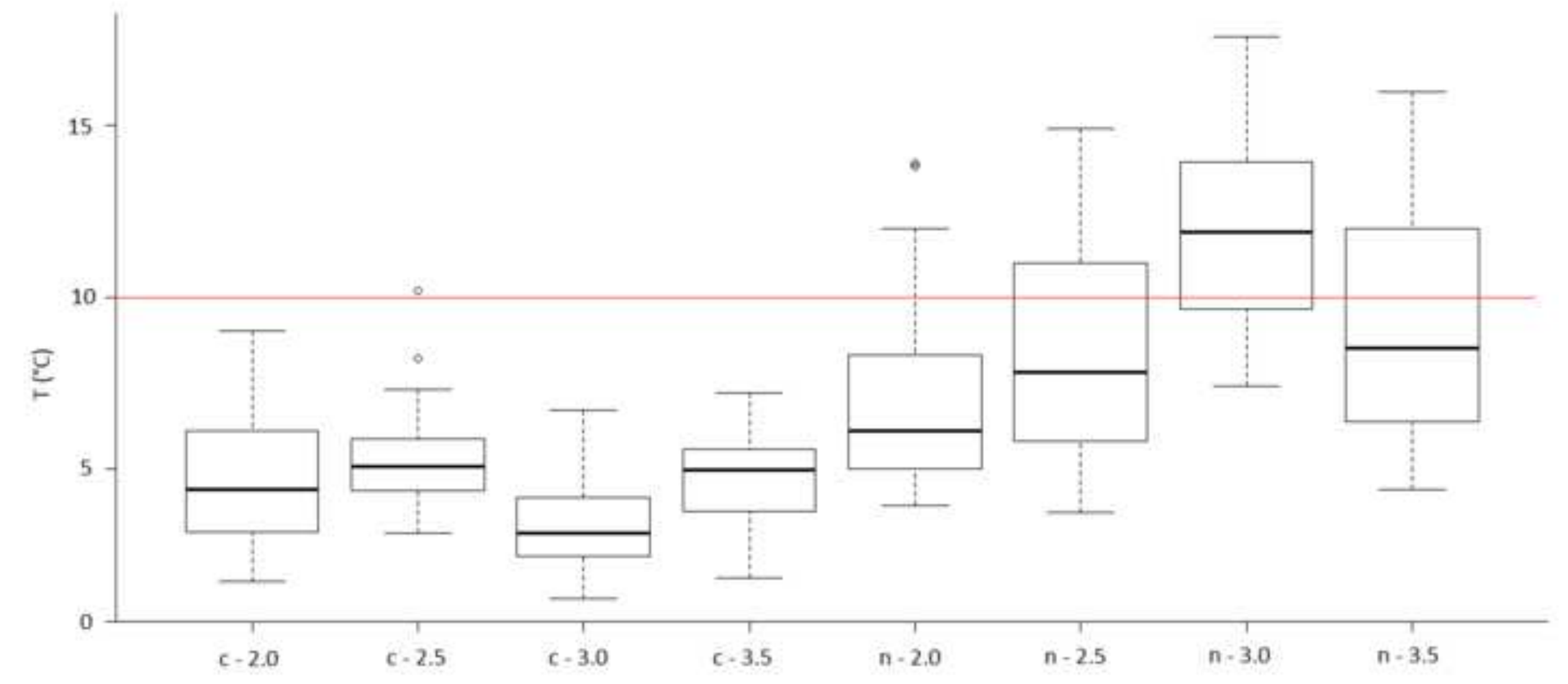




\section{Figure legends}

Figure 1.: Method of preparing cortical bone layer specimens from bovine ribs. *: cortical layer. \#: cancellous layer. White arrows and interrupted black lines: the represent the directions in which cutting was performed.

Figure 2.: Plan of the universal surgical guide for flat bone specimens, 3D-printed according to the same guidelines as the Smart Guide system's (Smart Dental Solutions Ltd., Szeged, Hungary) oral surgical implant guide.

Figure 3.: The experimental setting. (a): drilling. (b) and white arrow: external irrigation. (c): surgical guide. (d): cortical bone specimen. (e) and black arrow: direction and focus point of infrared thermometric measurement. (f): infrared thermometer. (g): display of the thermometer, visible to the video camera. (h): video camera. (i): adjustable and rotatable clamps for fixation.

Figure 4.: Boxplot diagram representing the distribution of the measured temperature rises. " $C$ " means cooling, followed by the diameter of the drill, while " $n$ " means no cooling, followed by the diameter of the drill. The red horizontal line represents the $10^{\circ} \mathrm{C}$ threshold. 


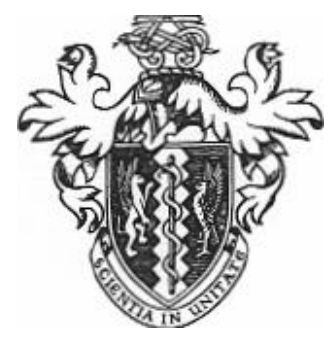

\section{The British Journal of Oral \& Maxillofacial Surgery}

ALL submissions to the journal are required to include statements of conflict of interest and confirmation of ethical approval / patient permission (if required). Please include the necessary statements on this form as well as in the manuscript - after the main text, before the reference section.

If there is no conflict of interest or ethical approval required, please state; do not leave the section/s blank.

\section{MANUSCRIPT TITLE: External cooling efficiently controls intraosseous temperature rise caused by}

\section{drilling in a drilling guide system: an in vitro study}

AUTHORS: Kristof Boa, Endre Varga Jr., DDS, PHD, MD, Gabor Pinter, MD, DDS, Akos Csonka, MD,

Istvan Gargyan, MD, Endre Varga, MD, $\mathrm{PhD}$

\section{Conflict of interest}

At the end of the text, under a subheading 'Conflict of interest statement' all authors must disclose any financial and personal relationships with other people or organisations that could inappropriately influence (bias) their work.

Examples of potential conflicts of interest include employment, consultancies, stock ownership, honoraria, paid expert testimony, patent applications/registrations, and grants or other funding.

\section{Conflict of Interest Statement}

Author Endre Varga Jr., DDS, PhD is the head of research \& development at DicomLab Kft.,Szeged, Hungary, manufacturer of 3D-printed patient-specific drilling guides.

Author Prof. Endre, Varga, MD, PhD is the senior consultant of computer-aided surgical techniques at DicomLab Kft., Szeged, Hungary, manufacturer of 3D-printed patient-specific drilling guides.

No other author has any financial connection with a commercial partner.

\section{Ethics}

Work on human beings that is submitted to the British Journal of Oral and Maxillofacial Surgery should comply with the principles laid down in the Declaration of Helsinki (for full details, please refer to the Guide for Authors online at http://ees.elsevier.com/bjoms). The manuscript should contain a statement that the work has been approved by the appropriate ethical committees related to the institution(s) in which it was performed and that subjects gave informed consent to the work. Studies involving experiments with animals must state that their care was in accordance with institution guidelines. Studies on patients or volunteers require ethics committee approval and informed consent, which should be documented in your paper.

\section{Patient confidentiality}

Patients have a right to privacy. Therefore identifying information, including patients' images, names, initials, or hospital numbers, should not be included in videos, recordings, written descriptions, photographs, and pedigrees unless the information is essential for scientific purposes and you have obtained written informed consent for publication in print and electronic form from the patient (or parent, guardian or next of kin where applicable). If such consent is made subject to any conditions, Elsevier must be made aware of all such conditions. Written consents must be provided to Elsevier on request. Even where consent has been given, identifying details should be omitted if they are not essential. If identifying characteristics are altered to protect anonymity, such as in genetic pedigrees, authors should provide assurance that alterations do not distort scientific meaning and editors should so note.

If consent for publication has not been obtained, personal details of patients included in any part of the paper and in any supplementary materials (including all illustrations and videos) must be removed before submission.

Ethics Statement / confirmation of patient permission

No patients, human samples or living animal subjects were involved as a subject in the preparation of the submitted work, thus requiring no ethical approval under the present rules of the University of Szeged, Szeged, Hungary. 


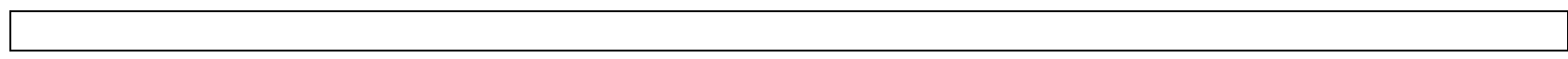


BRITISH JOURNAL OF ORAL \& MAXILLOFACIAL SURGERY

\section{Author contribution}

Manuscript Title: External cooling efficiently controls intraosseous temperature rise caused by drilling in a drilling guide system: an in vitro study

Please provide details in the table below of each author(s) contribution to the submitted manuscript

\begin{tabular}{|c|c|c|c|c|c|}
\hline AUTHORS & $\begin{array}{l}\text { Conception and } \\
\text { design of } \\
\text { study/review/case } \\
\text { series }\end{array}$ & $\begin{array}{l}\text { Acquisition of } \\
\text { data: laboratory } \\
\text { or } \\
\text { clinical/literature } \\
\text { search }\end{array}$ & $\begin{array}{l}\text { Analysis and } \\
\text { interpretation } \\
\text { of data } \\
\text { collected }\end{array}$ & $\begin{array}{l}\text { Drafting of } \\
\text { article and/or } \\
\text { critical } \\
\text { revision }\end{array}$ & $\begin{array}{l}\text { Final approval } \\
\text { and guarantor } \\
\text { of manuscript }\end{array}$ \\
\hline $\begin{array}{l}\text { Kristof Boa } \\
\text { MD }\end{array}$ & $\mathbf{x}$ & $\mathbf{x}$ & $\mathbf{x}$ & $\bar{x}$ & $\mathbf{x}$ \\
\hline $\begin{array}{l}\text { Endre Varga Jr. } \\
\text { DDS, PhD }\end{array}$ & $\mathbf{x}$ & & $\mathbf{x}$ & $\mathbf{x}$ & \\
\hline $\begin{array}{l}\text { Gabor Pinter } \\
\text { MD, DDS }\end{array}$ & $\mathbf{x}$ & $\mathbf{x}$ & $\mathbf{x}$ & & \\
\hline $\begin{array}{l}\text { Akos Csonka } \\
\text { MD }\end{array}$ & $\mathbf{x}$ & & & $\mathbf{x}$ & \\
\hline $\begin{array}{l}\text { Istvan Gargyan } \\
\text { MD }\end{array}$ & $\mathbf{x}$ & & & $\mathbf{x}$ & \\
\hline $\begin{array}{l}\text { Endre Varga } \\
\text { MD, PhD }\end{array}$ & $\mathbf{x}$ & & $\mathbf{x}$ & $\mathbf{x}$ & $\mathbf{x}$ \\
\hline
\end{tabular}


